\title{
The mathematical modeling of the process of hardening treatment of titanium blades of steam turbines
}

\author{
Alexander Filonovich ${ }^{1 *}$, Irina Vornacheva $^{1}$, Artem Chuichenko ${ }^{1}$, and Evgeny Bolotnikov ${ }^{1}$ \\ ${ }^{1}$ South-West State University, 305040, Kursk, 50 Let October, 94, Russia
}

\begin{abstract}
Mathematical models of the surface hardening of VT20 and OT4 titanium alloys by electrospark alloying have been developed. These models can be used in the design of technological processes for the manufacture of titanium blades for steam turbines.
\end{abstract}

\section{Introduction}

The development of power engineering, both in the Russian Federation and abroad, presupposes the ever wider use of turbine units of increased power, the steam pressure in which reaches $25 \mathrm{MPa}$, the steam flow rate is $500 \mathrm{~m} / \mathrm{s}$, and its temperature is $540^{\circ} \mathrm{C}$.

Power loads cause a complex stress state in the material of the blades (bending and twisting), in addition, tensile stresses arise in them from the centrifugal force due to the high speed of rotation of the rotor. Promising materials for large-sized blades in such turbines can be pseudo- $\alpha$-titanium alloys, in which the content of the unstable $\beta$-phase is much lower than in two-phase $(\alpha+\beta)$-titanium alloys, which ensures their higher heat resistance. It is known that electrospark coatings applied on pseudo- $\alpha$-titanium alloys have high wear resistance at temperatures up to $500^{\circ} \mathrm{C}$ and high corrosion resistance and can be used to increase the durability of turbine blades operating in a stream of superheated steam at high temperatures under conditions of drop impact erosional impact [1-19].

Taking into account the advantages and disadvantages of the electrospark alloying method, many enterprises are developing technological processes for strengthening (as well as restoration) of the leading and trailing edges of the working blades of the last stages of steam turbines using electrospark alloying [4-7]. There is very little information in the literature on the use of electrospark alloying for hardening turbine blades made of titanium alloys. Micrometallurgical processes occurring in the electric spark discharge zone can be changed, targeted synthesis of high-strength and heat-resistant compounds can be carried out, and complex composite coatings can be formed by varying the parameters and conditions of electrospark alloying.

An important task in the study of electrospark alloying of titanium alloys is to establish the regularities of the electrical erosion of electrode materials, especially the titanium cathode, as well as the regularities of the formation of coatings on the cathode, taking into

* Corresponding author : afil32@yandex.ru 
account the energy factors, the characteristics of the electrode materials and the interelectrode medium.

To establish the dependences of the influence of factors and conditions of the technological process of electrospark treatment on the quality of coatings on titanium blades of steam turbines, it is advisable to use methods of mathematical modeling [9-14].

\section{Materials and research methods}

Electrospark coatings were applied to titanium alloys VT20 and OT4 on an Elitron-22 setting with a PG-12N-03 electrode. The coating was carried out in air. Samples were cut from sheets of titanium alloys VT20 and OT4 $2 \mathrm{~mm}$ thick in the form of squares $10 \times 10 \mathrm{~mm}$ in size. Before starting the coating, the samples were cleaned with emery paper and degreased with acetone.

The regularities of the formation of the structure and properties of electrospark coatings on titanium alloys VT20 and OT4, obtained with the PG-12N-03 electrode, have been found. It was found that the highest specific gravity and the lowest porosity of the coating at a current strength of $8 \mathrm{~A}$, a discharge capacity of $0.6 \mu \mathrm{F}$ are achieved. Non-porous nickelbased coatings reinforced with borides, having high hardness, wear resistance and corrosion resistance are formed at these parameters [9-19].

Second-order rotatable planning, which allows you to represent the process under study with a sufficiently high reliability, was used to build the model. The following were chosen as independent variable factors that to the greatest extent determine the course of the electrospark alloying process:

$\mathrm{x}_{1}$ is specific time of coating application, $\mathrm{min} / \mathrm{cm}^{2}$;

$\mathrm{x}_{2}$ is the current in the electrical impulse, $\mathrm{A}$;

$\mathrm{x}_{3}$ is capacity of the electric spark discharge $\mu \mathrm{F}$.

Two characteristics of electrospark coatings, which are of the greatest value for the design of the technological process of hardening of steam turbine blades, were chosen as the output parameters of the model (optimization criteria). The first parameter is the thickness of the electrospark coating, which characterizes the productivity of the electrospark alloying process. The second parameter is the wear resistance of the electrospark coating, which characterizes the durability of the coating, i.e. service life of electrospark coated turbine blades.

Thus, we can write:

$\mathrm{y}_{\mathrm{I}}$ is coating thickness, mcm;

$\mathrm{y}_{\mathrm{II}}$ is relative wear resistance of the coating (standard titanium alloy VT20 without coating), conv. units.

For the developed model, the following restrictions were adopted. The maximum specific time of electrospark coating deposition $\left(\mathrm{x}_{1}\right)$ was taken equal to $1.8 \mathrm{~min} / \mathrm{cm}^{2}$ for reasons of rational productivity of the process. The turbine blade is coated in the area of the outer edge where the wear is most intense. The zone, hardened by the electrospark coating, has dimensions of $20 \times 5 \mathrm{~cm}$, an area of $100 \mathrm{~cm}^{2}$. The processing time of one blade with a specific coating time of $1.8 \mathrm{~min} / \mathrm{cm}^{2}$ will be 180 minutes (3 hours). Obviously, the duration of hardening of a titanium blade exceeds rational technological standards when the specific time of coating is exceeded. The limitation of the maximum value of the electric spark discharge current $\left(\mathrm{x}_{2}\right)$ to the value of $8 \mathrm{~A}$ is taken from considerations of the permissible porosity of the electric spark coating $(\approx 25 \%)$. Exceeding the specified current strength leads, as shown above, to a significant increase in the porosity of the coating and to an unacceptable decrease in its mechanical properties. The values of the discharge capacity $\left(\mathrm{x}_{3}\right)$, adopted in the developed model, are limited by the capabilities of the "Elitron-22" installation. 
Samples in the form of rollers made of VT20 alloy (for the SMTs-2 friction machine) were used in the experiment, on the forming surfaces of which electrospark coatings were applied with a PG-12N-03 alloying electrode in various modes. In this case, the diameter of the roller was measured before and after the application of the coating and, thus, the thickness of this coating was determined. Then the samples with electrospark coatings were tested for wear by friction on the surface of a hard-alloy roller (counterbody) with a saline solution with a finely dispersed quartz abrasive supplied to the friction zone.

\section{Results and discussion}

According to the results of the experiment, the coefficients in the regression equations (a mathematical model of the process under study) were calculated and their adequacy was checked according to the Fisher criterion. Adequate regression equations are:

For the thickness of the electrospark coating:

$$
\mathrm{y}_{\mathrm{I}}=63,05+10,13 \mathrm{x}_{1}+6,81 \mathrm{x}_{2}-1,62 \mathrm{x}_{1} \mathrm{x}_{2}-5,48 \mathrm{x}_{1}^{2}-1,22 \mathrm{x}_{2}{ }^{2}
$$

for the relative wear resistance of the coating:

$$
\mathrm{y}_{\text {II }}=2,46+2,44 \mathrm{x}_{1}+1,15 \mathrm{x}_{2}+0,19 \mathrm{x}_{1} \mathrm{x}_{2}+1,32 \mathrm{x}_{1}{ }^{2}-0,16 \mathrm{x}_{2}{ }^{2}
$$

These equations represent polynomial regression models of the process of electrospark coating PG-12N-03 deposition on titanium alloy VT20, which allow predicting the characteristics of this coating when changing the deposition modes.

As can be seen from the obtained regression equations (mathematical model), the specific time of coating deposition (the speed of movement of the alloying electrode over the surface to be hardened) has the greatest effect on both the thickness of the electrospark coatings and their wear resistance.

The strength of the pulsed current, which determines the mass of the electrode material applied to the substrate in one spark discharge, also has a rather noticeable effect on the output parameters of the resulting model (on the thickness and wear resistance of the coatings). As can be judged from the coefficients in the regression equations, this effect is about half that of the effect of the specific coating time. The capacity of an electric discharge within the investigated limits practically does not affect either the thickness of the electrospark coating or its wear resistance. Calculations showed that all the coefficients in front of the variable $\mathrm{x}_{3}$ (discharge capacity) turned out to be insignificant. The calculated dependences of the optimization criteria (output parameters of the model) on the independent factors adopted in the model are shown in figures 1 and 2.

The obtained dependences show, with a 95\% probability, the features of the course of the process of electrospark alloying of a titanium alloy with a change in external conditions - a change in the specific time of coating deposition and a change in the current of the spark pulse. It can be seen that the thickness of the electrospark coating from the nickel alloy PG$12 \mathrm{~N}-03$ on the titanium alloy VT20 monotonically increases with an increase in the specific alloying time and with an increase in the electric spark discharge current, at first very intensively, and then more and more slowly. The obtained dependencies can be used when assigning modes of electric spark hardening of titanium blades of steam turbines.

As for the relative wear resistance of electrospark coatings, as calculations show, according to the adopted model, the effect of the specific coating time and the effect of the current in the spark discharge on this characteristic are not the same. With an increase in the application time, the wear resistance of the coatings increases sharply; with an increase in the current strength, the wear resistance does not increase so much and almost linearly. Thus, the wear resistance of titanium turbine blades can be increased by a factor of 10 or 
more by increasing the specific coating time to $1.8-2.0 \mathrm{~min} / \mathrm{cm}^{2}$ at a spark discharge current of 8-9A.

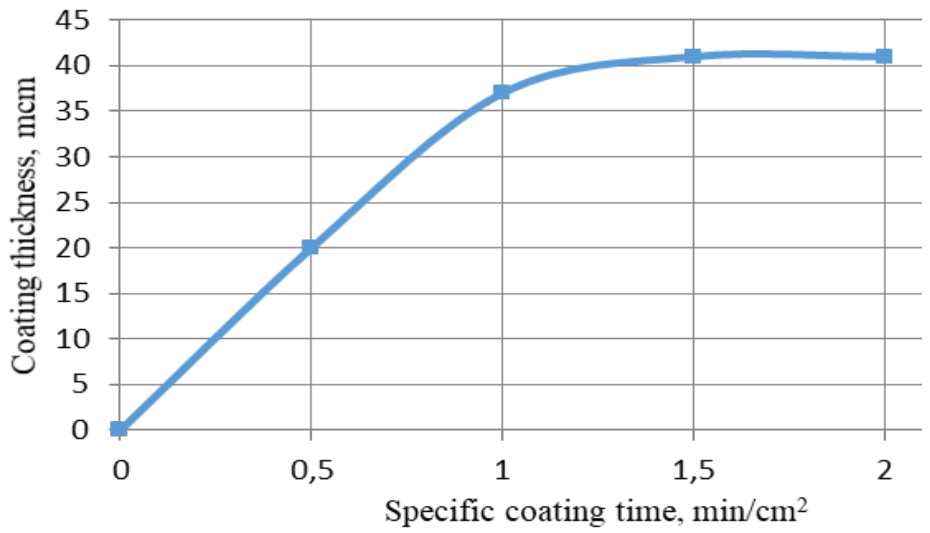

a

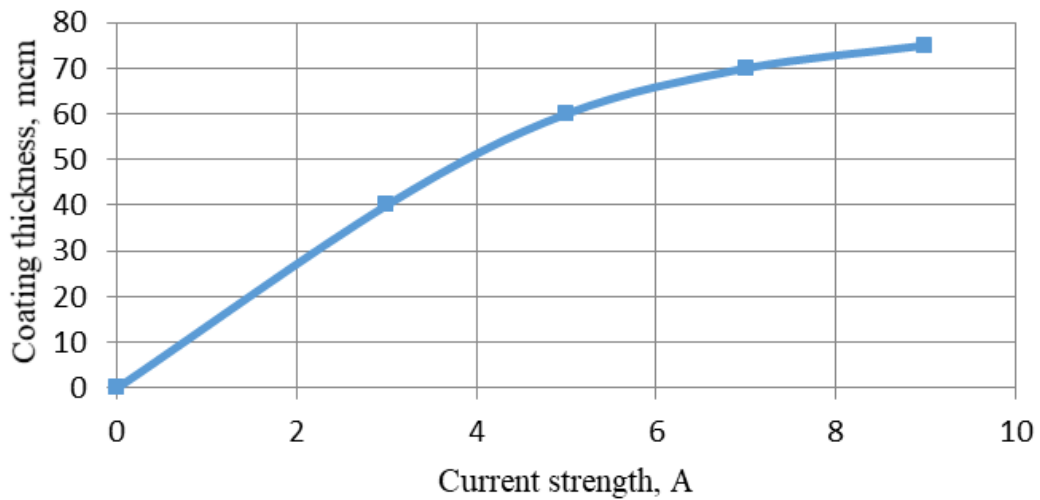

b

Fig. 1. Influence of the specific time of applying an electric spark coating (a) and the current of a spark pulse (b) on the thickness of the PG-12N-03 coating on titanium alloy VT20.

The legitimacy of using mathematical models for practical purposes depends on their adequacy. In our case, the adequacy of the model of the electrospark process is $95 \%$. This indicates that the calculated values obtained from the above equations (1) and (2) are in good agreement with the experimental data. Thus, a good agreement between the experimental and simulated data makes it possible to set the parameters of technological processes from the simulation data.

Visualization of graphs of functions in three-dimensional space is of interest. Such plots represent surfaces in a three-dimensional coordinate system. It is convenient to construct a three-dimensional image of the function (response surface) of the model under study using experiments carried out according to the algorithm for mathematical planning of the experiment, in our case, according to the second-order rotatable plan. Complex nonlinear relationships between variables can be discovered through such experiments. 

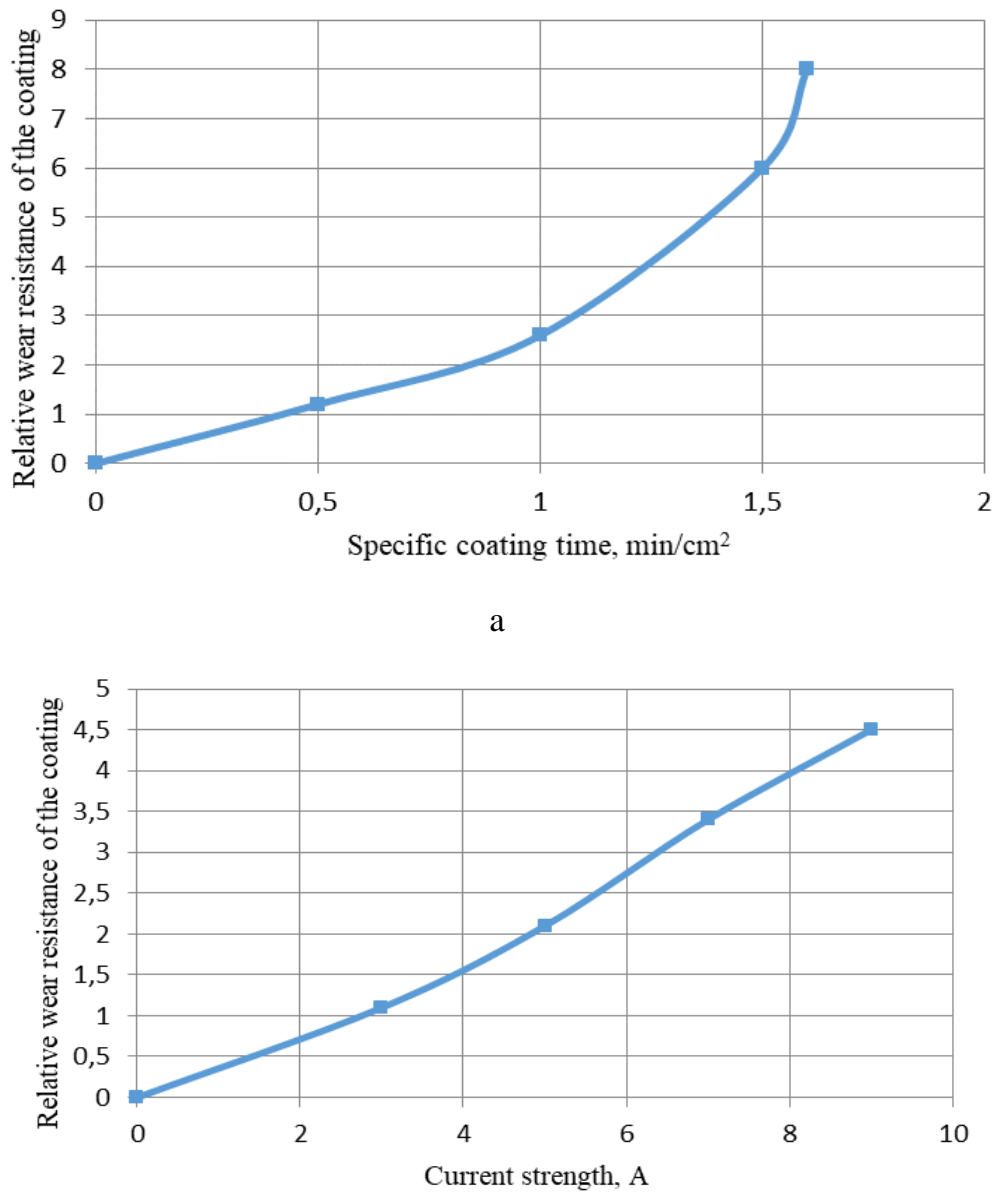

b

Fig. 2. Influence of the specific time of electrospark coating deposition (a) and the spark pulse current (b) on the wear resistance of the PG-12N-03 coating on the VT20 titanium alloy.

Visualization of functions of two variables has aesthetic (visual) and practical significance, since such functions act as mathematical models of various processes, for example, the process of electrospark alloying of a titanium alloy with a nickel electrode. After the model of this process becomes visible, it is much easier to analyze, since all the patterns of the phenomenon under study become visible and obvious.

In figures 3 and 4, three-dimensional images of mathematical models, the effect of the specific application time and the electric spark discharge current on the thickness of the PG-12N-03 electrospark coatings on the VT20 titanium alloy and their wear resistance are presented. These images were constructed using the SciLab computer program. 


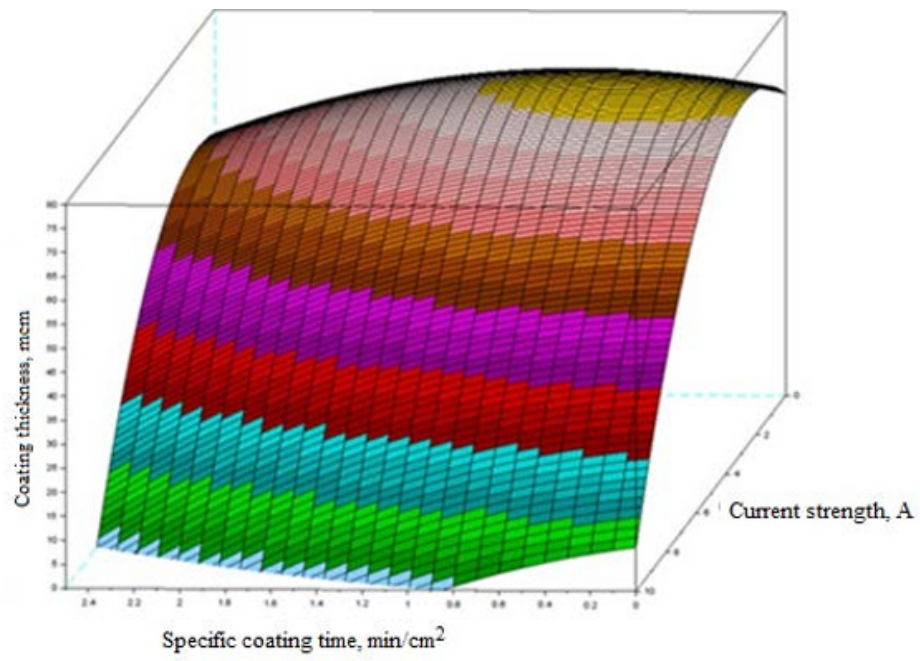

Fig. 3. Dependence of the thickness of the PG-12N-03 electric spark coating on the VT20 alloy on the specific application time and on the current strength in the electric spark discharge (calculation model)

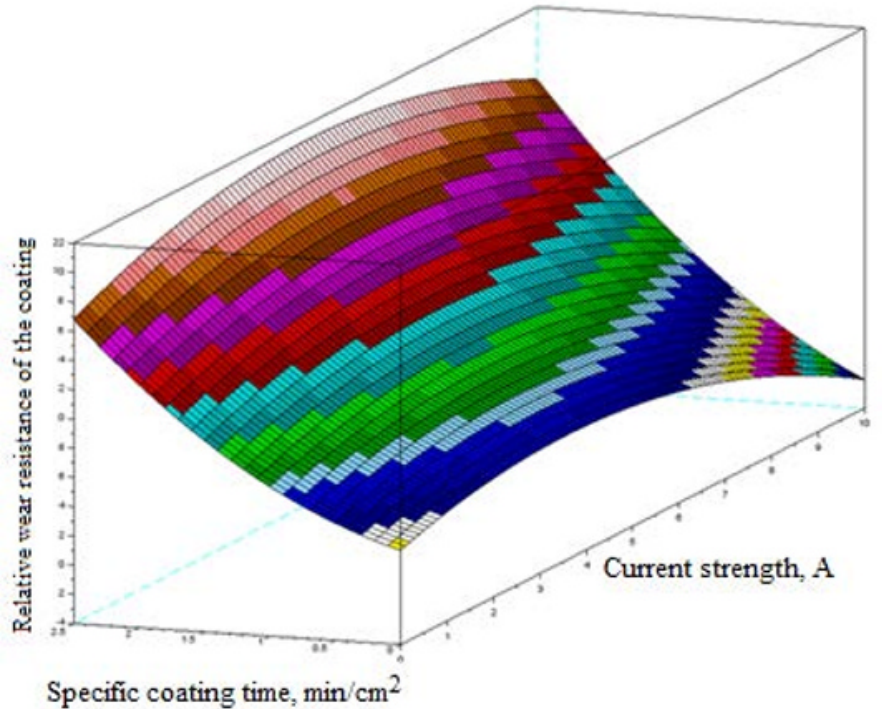

Fig. 4. Dependence of the relative wear resistance of the PG-12N-03 coating on the VT20 alloy on the specific application time and on the current strength in the electric spark discharge (calculation model).

\section{Conclusions}

1. For the design of technological processes for surface hardening of titanium blades of steam turbines, a mathematical model of electrospark alloying was developed. Second-order rotatable experimental design was used to build this model. It allows you to represent the process under study with a fairly high reliability $(\approx 90 \%)$.

2. The greatest effect on the productivity of the process (mass transfer of the electrode material) is exerted by the specific time of coating deposition, and the least effect is by 
the electric spark discharge current. The capacity of an electrospark discharge has practically no effect on both the thickness of the electrospark coatings and their wear resistance.

3. Visualization of the resulting model, carried out using the MatLab computer program, gives a visual representation of the process under study. Good agreement between the experimental and calculated (simulated) data makes it possible to set the parameters of technological processes for strengthening turbine blades according to the simulation data.

\section{References}

[1] V. Gadalov, I. Vornacheva, S. Voinash, V. Ignatenko, E. Remshev, The influence of thermocyclic treatment on the structure and mechanical properties of pseudo-alpha titanium alloys for steam turbine blades, Mat. Sc. Forum. Switzerland, pp. 117-124 (2021).

[2] V. Rezinskikh, A. Lebedeva, A. Bogachev, Serviceability Criteria for CorrosionDamaged LPC Blades of Steam Turbines, Electric stations 7, pp. 32-35 (1991).

[3] W. Wei-Ze, X. Fu-Zhen, Z. Kui-Long, Shan-Tung Tu, Failure analysis of the final stage blade in steam turbine, Eng. Fail. Analysis, 437, pp. 70-74 (2007).

[4] L. Zhuchenko, V. Kortenko, Yu. Sakhnin, On restoration of the resource of rotor blades and disks of steam turbines, Electric stations, 5 pp.21-24 (2001).

[5] V.I. Pokhmurskii, V.A. Vynar, C.B. Vasyliv, N.B Ratska, Effects of hydrogen exposure on the mechanical and tribological properties of $\alpha$-titanium surfaces, Wear, 306, pp.47-50 (2013).

[6] Yu. Belolipetskiy, R. Zaletaeva, L.Ostrovsky, Titanium alloys for steam turbine blades, Therm. Eng., 8, pp. 25-29 (1971).

[7] F. Gonserovsky, V. Silevich, Extension of the service life of units and parts of the flow path of the turbines of TPP and NPP, Heavy Eng., 10, pp.59-63 (2002).

[8] A. Karev, F. Khromchenko, P. Dolzhansky, Development and implementation of a highly efficient technology for the repair of steam turbine rotor blades Electric stations, 12, pp.16-20 (1999).

[9] I. Podchernyaeva, A. Verkhoturov, V. Panashenko, Electrospark and complex hardening of titanium surface, Sc. notes of the Komsomolsk-on-Amur St. Tech. Un., 1, pp.73-87 (2014).

[10] A. Hascalik, U. Çaydaş, Electrical discharge machining of titanium alloy (Ti-6Al-4V), App. Surf. Sc., 253 22, pp. 9007- 9016 (2007).

[11] L. Wang, Q. Zhang, X. Li, X. Cui, S. Wang, Severe-to-mild wear transition of titanium alloys as a function of temperature, Tr. Let., 53 3, pp. 511-520 (2014).

[12] X. Cui, Y. Mao, M. Wei, S. Wang, Wear characteristics of Ti-6Al-4V alloy at 20$400^{\circ} \mathrm{C}$, Tr. Trans., 55 2, pp.185-190 (2012).

[13] V. Gadalov, A. Filonovich, V. Shkatov, O. Turaeva, I. Vornacheva, A. Rozin, Description of the electrospark alloying process (Generalized model), News S.-W. St. Un. S.: Eng. and tech., 4 21, pp.58-66 (2016).

[14] V. Gadalov, S. Emel'yanov, I. Vornacheva, A. Filonovich, S. Safonov, Electroacoustic coating application to improve the performance of composites based on heat-resistant nickel alloys, Rus. Eng. Res., 37 9, pp.751-753 (2017). 
[15] V. Gadalov, E. Filatov, A. Gvozdev, N. Starikov, I. Makarova, I. Vornacheva, Investigation of the kinetics of the formation of a hardened surface layer, its structure and phase composition on a sintered alloy OT4, obtained by the method of electroerosive dispersion with local electrospark coating, Bul. Tula St. Un. Tech. sc., 11, pp.153-163 (2017).

[16] V. Gadalov, I. Vornacheva, A. Filonovich, E. Filatov, D. Alymov, Forecasting the reliability of metal structures using statistical modeling methods, Sc. Life, 14 , pp. 457-462 (2019).

[17] N. El-Tayeb, T. Yap, V. Venkatesh, P. Brevern, Modeling of cryogenic frictional behavior of titanium alloys using Response Surface Methodology approach, Mat. \& Des. 30 10, pp. 4023-4034 (2009).

[18] V. Gadalov, I. Vornacheva, I. Makarova, E. Filatov, E. Elnikov, R. Erokhin, Modernization of the process of electrospark alloying technology, Rep. Rec. Mod., 5, pp. 41-48 (2019).

[19] V. Gadalov, A. Filonovich, I. Vornacheva, M. Muratov, On the influence of electrospark alloying modes on the kinetics of mass transfer of the alloying electrode material on titanium alloys for steam turbine blades, Rep. Rec. Mod., 10, pp. 38-43 (2020). 